\title{
A DESCRIPTIVE STUDY OF SURGICAL MANAGEMENT OF ILEAL PERFORATION
}

\author{
Yogesh Kumar Yashaswi ${ }^{1}$, Vibhuti Bhushan ${ }^{2}$, Prem Prakash ${ }^{3}$, Manish Kumar $^{4}$, Pooja Nupur $^{5}$ \\ ${ }^{1}$ Senior Resident, Department of Surgery, IGIMS, Patna. \\ ${ }^{2}$ Associate Professor, Department of Surgery, IGIMS, Patna. \\ ${ }^{3}$ Associate Professor, Department of Surgery, IGIMS, Patna. \\ ${ }^{4}$ Assistant Professor, Department of Surgical Oncology, IGIMS, Patna. \\ ${ }^{5}$ Senior Resident, Department of Skin and V. D, NMCH, Patna.
}

\section{ABSTRACT}

\section{BACKGROUND}

Enteric perforation is one of the most frequently encountered acute surgical emergency in Northern India and always warrants operative intervention. But the kind of intervention, whether primary repair or ileostomy is a contentious issue.

\section{MATERIALS AND METHODS}

120 cases of ileal perforation were studied in retrospective manner from August 2015 to July 2016 to gather information on demographic profile, clinical presentation and laboratory data. Details were obtained for operative findings and kind of operative intervention done and postoperative course of the patients. Based on the kind of operative intervention received, patients were divided into four groups.

\section{RESULTS}

Ileal perforation occurred in young males (age 29.2 \pm 7.9 years). Male [M] Female [F] ratio has been found to be M: F, 2.33: 1 . In our study $60 \%$ of patients had Widal positive supporting typhoid aetiology; $50 \%$ of patients underwent primary closure, while $30 \%$ underwent ileostomy. Nature of clinical presentation, laboratory data and operative findings in both groups has been analysed.

\section{CONCLUSION}

We have carried out this study to label some of the preoperative and intraoperative factors, which can serve as a guideline for decision making in operative intervention in a specific patient.

\section{KEYWORDS}

Ileal Perforation, Ileostomy, Primary Closure, Typhoid.

HOW TO CITE THIS ARTICLE: Yashaswi YK, Bhushan V, Prakash P, et al. A descriptive study of surgical management of ileal perforation. J. Evolution Med. Dent. Sci. 2017;6(80):5637-5640, DOI: 10.14260/jemds/2017/1222

\section{BACKGROUND}

Typhoid is a febrile illness caused by faeco-oral transmission of gram negative bacillus, salmonella enterica serovar typhi from chronic carrier. It can cause various surgical complications like gastrointestinal haemorrhage, ileal perforation, etc. Hollow viscus perforation is a full thickness slit in bowel wall leading to leakage of intestinal contents into peritoneal cavity, resulting in contamination with digestive enzymes, chemicals and bacteria to produce peritonitis. Ileal perforation peritonitis due to typhoid forms bulk load of surgical emergencies. To treat such illness, it is a challenge to a surgeon as they occur in a younger age group and is associated with high morbidity and mortality. The operative management of ileal perforation includes either an approximation of the perforation margins known as primary repair or by exteriorisation of the involved segment to form stoma/ileostomy.

'Financial or Other Competing Interest': None.

Submission 30-08-2017, Peer Review 24-09-2017,

Acceptance 30-09-2017, Published 05-10-2017.

Corresponding Author:

Dr. Pooja Nupur,

Senior Resident,

Department of Skin and V. D,

Nalanda Medical College and Hospital,

Agam Kuan, Patna-800007.

E-mail: pooja.nupur.it@gmail.com

DOI: $10.14260 /$ jemds/2017/1222 anastomosis in a sense that it takes out diseased segment and also it is better to have a single suture line than multiple. Also, some authors have described primary closure and proximal side-to-side ileotransverse anastomosis. ${ }^{1}$ Several perceptions and concerns related to the stoma effect and the quality of life of the patient during the interval between the primary surgery and the stoma closure has been documented. This apparently disfiguring surgery causes change in body image and significantly influences the physical, mental, emotional and social life of the stoma patients. ${ }^{2}$ This makes decision on whether to do a primary repair or diversion ileostomy, a controversial subject in emergency surgery. The study was carried out at Indira Gandhi Institute of Medical Sciences, Sheikhpura, Patna.

\section{Objective}

The objective of the study is to list the preoperative and intraoperative factors, which can serve as a guideline in decision making for type of operative intervention in cases of ileal perforation.

\section{MATERIALS AND METHODS}

This descriptive study was conducted in a retrospective manner from August 2015 to July 2016 in the Department of Surgery, Indira Gandhi Institute of Medical Sciences, Sheikhpura, Patna and data was collected from Medical Records Department. 


\section{Inclusion Criteria}

All patients admitted via emergency with diagnosis of perforation peritonitis, who on surgery were found to have ileal perforation were included.

\section{Exclusion Criteria}

Patients with age less than 12 years with peritonitis due to appendicular perforation, peptic ulcer perforation, traumatic ileal perforation etc. were excluded.

Initial diagnosis of perforation peritonitis in all patients was established by presence of peritoneal signs and/or evidence of gas under both domes of diaphragm on an erect chest X-ray PA view. Data on demographic profile, symptoms and signs was recorded. Data on Widal test and blood culture was obtained from microbiology department. Relevant haematological and biochemical investigations were recorded. Operative notes were studied from medical record to obtain findings of amount and type of peritoneal contamination, number, site and size of perforation, presence of bowel wall oedema. Type of procedure performed was as following (Table 1). Group A- Primary closure in 2 layers using 2 - 0 or 3 - 0 Vicryl full thickness and 2 - 0 or 3 - 0 silk seromuscular. Group B- Primary closure with proximal diversion ileostomy or exteriorization of perforation. Group C- Resection and anastomosis. Group D- Only flank drain placement.

Postoperative course in the hospital like timing of starting oral feeds, day of start of ileostomy function and average length of stay was recorded. Postoperative complications like wound infection, wound dehiscence, reperforation or anastomotic leak, septicaemia, respiratory complications and mortality was recorded.

Statistical analysis was performed by IBM-compatible Statistical Package for the Social Sciences (SPSS) version 20.0.

\section{RESULTS}

A total of 120 patients with ileal perforation peritonitis were included. Most patients, 84 were male with Male-to-Female ratio [M: F] being 2.33: 1. Based on the surgical management done, the distribution of patients across different groups is as follows. Majority of patients had undergone primary closure (Group A, n= 60,50\%) or ileostomy (Group B, $n=36,30 \%$ ); 20 patients (Group C) underwent resection and anastomosis due to either multiple perforation or unhealthy bowel; 4 patients (Group D) despite adequate fluid resuscitation did not show improvement in systolic blood pressure, needed inotropic support and were unfit for general anaesthesia and were treated with placement of flank drain at bedside. As the numbers in Group C and D were less, further comparison was carried out between Group A and Group B. Age incidence in both groups were comparable with mean age in Group A $28.78 \pm 7.6$ and Group B $30.45 \pm 8.5$ years. Clinically, the onset of peritonitis is taken from the time of onset of acute pain abdomen. With more delay in presentation, the chances of morbidity and mortality increases. Based on presentation timing, patients were classified into early or late presentation as shown in Table 2. It suggests that more number of patients within 72 hours of onset underwent primary repair, while those coming after 72 hours underwent ileostomy. Distribution of signs and symptoms, haematology and microbiology in both groups are represented in Table 3. Fever was a consistent symptom in both groups and was predominantly of high grade and intermittent in nature with a mean duration of $9.23 \pm 3.4$ days. This points to likely occurrence of perforation in enteric fever patients in 2nd week of disease. Other symptoms like vomiting, abdominal distension and constipation were present in comparable numbers in both groups. On the basis of systolic blood pressure on admission, more number of patients (Group B vs Group A; $83.33 \%$ vs 23.33\%) in ileostomy group had presented with shock (Systolic BP $<90 \mathrm{~mm}$ ). Data on haematologic profile was comparable in both groups (Table 3). Microbiology investigation of both groups revealed 52 patients had Widal positive, while only 30 had blood culture positive. This again points to disease being in $2 \mathrm{nd}$ week in our subset of patients.

\begin{tabular}{|c|c|c|}
\hline Sl. No. & Group Name & Type of Procedure Done \\
\hline 1 & Group A & Primary closure in 2 layers \\
\hline 2 & Group B & Ileostomy \\
\hline 3 & Group C & Resection and anastomosis \\
\hline 4 & Group D & Flank drain placement \\
\hline \multicolumn{3}{|c|}{ Table 1. Division on the Basis of Operative Intervention } \\
\hline
\end{tabular}

\begin{tabular}{|c|c|c|c|}
\hline $\begin{array}{c}\text { Sl. } \\
\text { No. }\end{array}$ & Group & $\begin{array}{c}\text { Early Presentation } \\
\text { (< 72 hrs.) }\end{array}$ & $\begin{array}{c}\text { Late Presentation (> } \\
\mathbf{7 2} \text { hrs.) }\end{array}$ \\
\hline 1 & A & $39(65 \%)$ & $21(35 \%)$ \\
\hline 2 & B & $11(30.55 \%)$ & $25(69.44 \%)$ \\
\hline \multicolumn{2}{|c|}{ Table 2. Timing of Presentation to the Hospital } \\
\hline
\end{tabular}

\begin{tabular}{|c|c|c|c|}
\hline $\begin{array}{c}\text { Sl. } \\
\text { No. }\end{array}$ & $\begin{array}{c}\text { Symptoms/ Signs/ } \\
\text { Lab Test }\end{array}$ & $\begin{array}{c}\text { Group A } \\
\text { n (\%) }\end{array}$ & $\begin{array}{c}\text { Group B } \\
\text { n (\%) }\end{array}$ \\
\hline 1 & Fever & $58(96.66 \%)$ & $35(97.22 \%)$ \\
\hline 2 & Vomiting & $40(66.66 \%)$ & $20(55.55 \%)$ \\
\hline 3 & Abdominal distension & $60(100 \%)$ & $35(97.22 \%)$ \\
\hline 4 & Constipation & $55(91.66 \%)$ & $35(97.22 \%)$ \\
\hline 5 & Sys. BP <90 mmHg & $14(23.33 \%)$ & $30(83.33 \%)$ \\
\hline 6 & Guarding/ Rigidity & $60(100 \%)$ & $30(83.33 \%)$ \\
\hline 7 & Hb (<9 gm/dL) & $52(86.66 \%)$ & $33(91.67 \%)$ \\
\hline 8 & $\begin{array}{c}\text { Total WBC count }> \\
11000 / m m 3)\end{array}$ & $43(71.66 \%)$ & $28(77.77 \%)$ \\
\hline 9 & Widal positive & $32(53.33 \%)$ & $20(55.55 \%)$ \\
\hline 10 & $\begin{array}{c}\text { Blood culture (grows S. } \\
\text { typhi) }\end{array}$ & $20(33.33 \%)$ & $10(27.77 \%)$ \\
\hline \multicolumn{4}{|c|}{ Table 3. Clinicopathologic Profile } \\
\hline \multicolumn{4}{|c|}{} \\
\hline
\end{tabular}

On study of operative intervention, it was found that majority 96 (80\%) had solitary perforation, while 20 $(16.66 \%)$ patients had multiple perforations (in 4 patients who underwent tube laparostomy, data was not available). All patients with multiple perforations underwent resection and anastomosis (Group C). All patients in Group A and Group $B$ had solitary perforation and other operative parameters are compared in Table 4. Based on intraoperative findings, it was found that patients with intraperitoneal contamination $>1500 \mathrm{~mL}$ with faeculent smell, site of perforation within 10 $\mathrm{cm}$ of ileocaecal junction and with bowel wall oedema were preferably treated with ileostomy rather than primary closure. Postoperatively, median day of start of oral feeds was 3rd postop day. Postoperative complications are represented in Table 5. Wound infection rates (Group B: Group A 50\%:33.3\%), respiratory complications (Group B: Group A 19.44\%: 6.67\%) were higher in ileostomy group, while burst abdomen was comparable in both groups. It is notable that 4 $(6.67 \%)$ reperforations were recorded in primary closure group as compared to Nil in ileostomy group, which certainly 
points to an advantage of ileostomy over primary closure in avoiding a dreadful and often deadly complication. More deaths (Group B: Group A 13.88\%: 5.0\%) were recorded in ileostomy group.

\begin{tabular}{|c|c|c|c|}
\hline $\begin{array}{c}\text { Sl. } \\
\text { No. }\end{array}$ & $\begin{array}{c}\text { Operative } \\
\text { Parameter }\end{array}$ & $\begin{array}{c}\text { Group A } \\
\text { n \% }\end{array}$ & $\begin{array}{c}\text { Group B } \\
\text { n \% }\end{array}$ \\
\hline 1 & $\begin{array}{c}\text { Peritoneal contaminant } \\
\text { fluid (> 1500 mL) }\end{array}$ & $21(35 \%)$ & $29(80.55 \%)$ \\
\hline 2 & $\begin{array}{c}\text { Faeculent smell of fluid } \\
\text { present }\end{array}$ & $10(16.66 \%)$ & $27(75 \%)$ \\
\hline 3 & $\begin{array}{c}\text { Site of perforation < } 10 \mathrm{~cm} \\
\text { from ileocaecal junction }\end{array}$ & $4(6.66 \%)$ & $29(80.55 \%)$ \\
\hline 4 & $\begin{array}{c}\text { Site of perforation > } 10 \mathrm{~cm} \\
\text { from ileocaecal junction }\end{array}$ & $56(93.33 \%)$ & $7(19.44 \%)$ \\
\hline 5 & Bowel wall oedema present & $7(11.66 \%)$ & $28(77.77 \%)$ \\
\hline \multicolumn{3}{|c|}{ Table 4. Comparison of Operative Findings } \\
\hline
\end{tabular}

\begin{tabular}{|c|c|c|c|}
\hline $\begin{array}{l}\text { Sl. } \\
\text { No. }\end{array}$ & $\begin{array}{l}\text { Postoperative } \\
\text { Complication }\end{array}$ & $\begin{array}{c}\text { Group A } \\
\text { n \% }\end{array}$ & $\begin{array}{c}\text { Group B } \\
\text { n \% }\end{array}$ \\
\hline 1 & Wound infection & $20(33.3 \%)$ & $18(50 \%)$ \\
\hline 2 & Burst abdomen & $6(10 \%)$ & $4(11.11 \%)$ \\
\hline 3 & Reperforation & $4(6.66 \%)$ & 0 \\
\hline 4 & Intra-abdominal abscess & $1(1.66 \%)$ & $2(5.55 \%)$ \\
\hline 5 & Respiratory complication & $4(6.66 \%)$ & $7(19.44 \%)$ \\
\hline 6 & Deaths & $3(5 \%)$ & $5(13.88 \%)$ \\
\hline \multicolumn{4}{|c|}{ Table 5. Postoperative Complications } \\
\hline
\end{tabular}

\section{DISCUSSION}

Enteric fever is a systemic disease caused by Salmonella typhi and Salmonella paratyphi and is characterised by fever, abdominal pain, relative bradycardia with involvement of the lymphoid tissues. ${ }^{3}$ The organism passes through the Peyer's patches without causing inflammation. Multiplication occurs in the reticuloendothelial system for $10-14$ days. Seeding occurs in the blood stream corresponding to the clinical onset. During the 2nd week of illness, bacteria reach the gut and localise in Peyer's patches. Ulceration and "mesenteric adenitis" occur. Necrotic areas appear in lymphoid tissue. ${ }^{4,5}$ The deadliest complication in typhoid, i.e. haemorrhage and perforation happen due to necrosis of Peyer's patches in the terminal ileum. Ileal perforation peritonitis is a frequently encountered surgical emergency in Northern India. It is reported to constitute the fifth common cause of abdominal emergencies due to high incidence of enteric fever and tuberculosis in these regions. ${ }^{6}$ Small bowel perforations most commonly affect the young males in the prime of their life. In the present study, mean age was $29.2 \pm 7.9$ years with a Male:Female ratio of 2.33: 1. Similar ratio of 3: 1 has been reported by Wani et al, ${ }^{7}$ whereas a higher ratio of $6.5: 1$ by $S$ Mittal et $\mathrm{al}^{6}$ and 4: 1 by Talwar et al $^{8}$ 6.4: 1 reported by Beniwal et al. ${ }^{9}$ Affliction of young males has various socioeconomic implication, as they are often daily wage workers and sole breadwinners for their family. As pointed by duration of fever and widal positivity, our study suggests usual timing of occurrence of perforation in the 2 nd week of disease.

Also clinching evidence of typhoid being the cause of perforation in high percentage of patients. In Western population, immune mediated diseases like Crohn's disease, Celiac disease, Vasculitis, Collagenous sprue are common cause of small bowel perforation than infectious diseases. ${ }^{10}$ Historically, conservative management of enteric perforations was popular, but was associated with high morbidity and mortality. Dawson found that at laparotomy there was no tendency towards walling off by the omentum or any attempt at healing of the perforation as in other reports. ${ }^{11}$ Furthermore, with paralytic ileus occurring in peritonitis of this magnitude, there is continuous leak of small bowel contents into the peritoneal cavity from the dilated small bowel loops. Treatment has evolved into emergent surgical intervention. Type of operative intervention for ileal perforation has been pure prerogative of operating surgeons and a varied approach has been described. Zida et al ${ }^{12}$ recommended creation of ileostomy as primary therapy for ileal perforation peritonitis as it reduces morbidity and mortality, whereas $\mathrm{Pal}$ et $\mathrm{al}^{13}$ recommended primary closure and side-to-side ileotransverse for better results. No clinching evidence is available either in support of primary closure, which has the advantage of less postoperative morbidity or ileostomy as a lifesaving procedure, as it avoids reperforation, thus avoiding a potentially fatal postoperative complication. The decision regarding the type of surgery needs to balance the risk of an anastomotic dehiscence to the inconvenience of bowel exteriorisation. ${ }^{14,15}$ Primary repair is advantageous for less postoperative morbidity and mortality. But a small number of patients have intestinal leakage, which can lead to intra-abdominal abscess or enterocutaneous fistula and can be devastating. Making an ileostomy gives definitive protection from intestinal leakage, but has its own inherent complication like dermatitis, stomal retraction, parastomal herniation and also is associated with psychological impact. Pardeep Saini et al assessed common social concerns like feeling sexually unattractive, need to know toilet location, embarrassed about body image, disturbed sleep during night, limited choice of clothes, anxiety about pouch loosening, anxiety about pouch filling, staying away from home overnight which affect quality of life. ${ }^{2}$ Hence, risk versus benefit in a patient specific scenario should be addressed. Thus, onus often lies on the operating surgeon to choose between the two procedures and 'choose wisely.' Various preoperative and intraoperative findings may help the surgeon make a decision. Among preoperative parameter, timing of presentation is very important. Our study suggests that a delay of more than 72 hours increases likelihood of complications, so ileostomy should be preferred in such patients. Another important finding was systolic blood pressure on admission. It is better to perform ileostomy on patients who present in shock. We also suggest that any patient who is anaemic and has low total serum protein level is likely to have reperforation and hence should be chosen for ileostomy. Murray et al suggested that presence of anaemia and hypoalbuminaemia along with an increased lag period of $>72$ hours, points towards poor general condition of the patient at presentation and such patients have been shown to have better outcome with bowel exteriorisation. ${ }^{16}$ Choice of surgical intervention also depends on various operative parameters, but is a test of surgeon's experience. In the present study, we found certain findings like high volume of intraperitoneal contamination $(>1500$ $\mathrm{mL}$ ), faeculent smell of the contaminant, presence of bowel wall oedema, perforations close to ileocaecal junction are likely to benefit with an ileostomy. Prashant et al explains high volume, faeculent intraperitoneal collection and bowel wall oedema are unfavourable factors for holding sutures and 
such cases are better managed by exteriorisation. ${ }^{15}$ Gupta et al suggested primary closure is only done when patient presents early and the bowel looks healthy. Sepsis and bowel oedema makes suturing hazardous, so primary closure should be avoided in patients presenting late. They concluded that presence of bowel oedema warranted exteriorisation. ${ }^{17}$ Jain et al opinioned that the suture line presents a considerable risk of intestinal leakage, if the suture line does not heal satisfactorily due to the presence of one or more adverse factors. They advocated no suture line in the procedure seems to be a better option in adverse patient conditions. ${ }^{18}$ According to Gurjit Singh et al degree of faecal contamination, general health status of patient, number and location of perforation were main deciding factors for selecting the type of surgical operations. ${ }^{19}$ When there was minimum peritoneal contamination with single perforation quite far away from ileocaecal junction with good general health, simple closure of perforation in two layers after excision of edges should be advocated. However, in moderate peritoneal contamination with multiple perforations very close to each other and perforation in close proximity to ileocaecal junction, resection with end to side ileotransverse anastomosis was resorted.19 Previously, many authors have advocated use of an ileotransverse anastomosis in adverse situations to reduce stress on the primary closure suture line. But the authors feel a no suture line approach would be better.

\section{CONCLUSION}

We conclude that early surgical intervention is mandatory for good results. Although, there can be dilemma over choice of surgery, but various parameters can help in guiding to make a decision over choice of Primary Closure vs Ileostomy. Preoperative parameters namely delayed presentation $(>72$ hours), presence of shock at admission, anaemia, hypoproteinaemia should guide one to choose Ileostomy over Primary Closure. Similarly, operative findings of high volume of intraperitoneal contamination ( $1500 \mathrm{~mL}$ ), faeculent smell, perforations close (within $10 \mathrm{cms}$ ) to ileocaecal junction and presence of significant bowel wall oedema, one should prefer to make an ileostomy. Making an ileostomy in such patients may sometimes be equivalent to snatching patient's life from hands of death.

\section{REFERENCES}

[1] Prasad PB, Choudhury DK, Prakash O. Typhoid perforation treated by closure and proximal side-toside ileotransverse colostomy. Journal of the Indian Medical Association 1975;65(11):297-9.

[2] Saini P, Gaba R, Faridi MS, et al. Quality of life of patients after temporary ileostomy for ileal perforation- a questionnaire based study. Indian J Surgery 2014;76(1):38-43.
[3] Ananthnarayanan R, Paniker CKJ. Enterobacteriaceae III: Salmonella. Textbook of medical microbiology. $8^{\text {th }}$ edn. Hyderabad: Universities Press 2009:288-300.

[4] Shah S, Gandhi JP. Role of ileostomy in enteric perforation. IJSS Journal of Surgery 2015;1(1):10-5.

[5] Ugochukwu AI, Amu OC, Nzegwu MA. Ileal perforation due to typhoid fever - review of operative management and outcome in an urban centre in Nigeria. International Journal of Surgery 2013;11(3):218-22.

[6] Mittal S, Singh H, Munghate A, et al. A comparative study between the outcome of primary repair versus loop ileostomy in ileal perforation. Surgery Research and Practice Article ID 729018, 2014;2014: p. 4.

[7] Wani RA, Parray FQ, Bhat NA, et al. Nontraumatic terminal ileal perforation. World Journal of Emergency Surgery 2006;1:7.

[8] Talwar S, Sharma RK, Mittal DK, et al. Typhoid enteric perforation. Australian and New Zealand Journal of Surgery 1997;67(6):351-3.

[9] Beniwal U, Jindal D, Sharma J, et al. Comparative study of operative procedures in typhoid perforation. Indian Journal of Surgery 2003;65(2):172-7.

[10] Freeman HJ. Spontaneous free perforation of the small intestine in adults. World J Gastroenterology 2014;20(29):9990-7.

[11] Dawson JH. Surgical management of typhoid perforation of ileum. Ann J Surg 1970;36(10):620-2.

[12] Zida M, Ouedraogo T, Bandre E, et al. Primary ileostomy for typhoid-related ileal perforation: a 62 case series in Ouagadougou, Barkina Faso. Med Trop (Mars) 2010;70(3):267-8.

[13] Pal DK. Evaluation of best surgical procedures in typhoid perforation: an experience of 60 cases. Trop Doct 1998;28(1):16-8.

[14] Castillo RJ, Zolezzi MA, Daniel MP, et al. Primary repair vs. colostomy in colon injuries. Cir Ciruj 2009;77(5):365-8.

[15] Pipariya PR, Menon AV, Chandel H. A comparative study of primary repair vs. stoma in emergency surgeries: an institutional experience. Sch J App Med Sci 2015;3:1326-31.

[16] Murray JA, Demetriades D, Colson M, et al. Colonic resection in trauma: colostomy versus anastomosis. Journal of Trauma 1999;46(2):250-4.

[17] Gupta S, Kaushik R. Peritonitis - the Eastern experience. World Journal of Emergency Surgery 2006;1:13.

[18] Jain BK, Arora H, Srivastava UK, et al. Insight into the management of non-traumatic perforation of the small intestine. J Infect Dev Ctries 2010;4(10):650-4.

[19] Singh G, Dogra BB, Jindal N, et al. Non-traumatic ileal perforation: a retrospective study. J Family Med Prim Care 2014;3(2):132-5. 